\title{
Study on the breaking process of jointed rock mass by disc cutters based on digital image correlation and infrared thermography
}

\author{
Xie Junning ${ }^{1, a}$, Liu Bolong ${ }^{1, b^{*}}$, and Zeng Nianchang ${ }^{1, c}$ \\ ${ }^{1}$ School of Civil Engineering, Chongqing University,Chongqing, China
}

\begin{abstract}
Jointed rock masses are frequently encountered during the TBM excavation. To investigate the rock breakage mechanism of jointed rock mass by disc cutter and precursory information before rock failure, a series of indentation tests were performed on shear rheological test system. During the test, breaking process of specimens were recorded by digital image correlation system and thermal infrared imager simultaneously. Therefore, the strain fields and thermal infrared images of jointed rock mass by disc cutters were obtain. The experimental results show that the failure process of jointed rock mass can be divided into four stages: compaction stage, linear elastic stage, residual failure transition stage and post-failure stage. Besides, the characteristic of strain fields shows a good accordance with that of infrared radiation temperature fields at each stage. The failure of rock samples is dominated by shear failure, and the localized temperature rise is an important infrared precursor of rock fracture and instability. The experimental results are of great significance to the deep understanding of the breaking mechanism of jointed rock mass and warnings of engineering disasters.
\end{abstract}

\section{Introduction}

The full-face Tunnel Boring Machine (TBM) is widely used in the construction of urban subway for its high efficiency and little disturbance to the surrounding environment. As the joint conditions encountered during the tunnelling have a significant impact on the penetration rate of TBM, it is of great significance to reveal the mechanism of rock breaking. In addition, instability of surrounding rock during the tunnelling is also frequently encountered. Therefore, investigation on the abnormal precursors of jointed rock masses is essential.

In order to study the rock breaking mechanism of cutter, Gnirk et al. ${ }^{[1]}$ and Maurer et al. ${ }^{[2]}$ analyzed the failure characteristics of rock mass in the test of cutter penetration. It was found that rock mass was damaged under the action of tension and shear deformation of joint planes. Sikasskie et al. ${ }^{[3-4]}$ and Paul et al. ${ }^{[5]}$ thought that the rock chips were formed along the fractures, which propagated with a certain dip angle under the cutter tip; Tian et al. ${ }^{[6]}$ carried out bidirectional loading test on granite samples with holes to simulate roadway rockburst. The minimum and average infrared radiation temperature of the rock specimens were analysed. It was found that the evolution law of infrared radiation temperature was closely related to the process of rockburst inoculation and occurrence. Song et al. ${ }^{[7]}$ quantitatively studied the evolution characteristics of strain field and strain localization during the failure

* Corresponding author: ${ }^{b} 20171601009 @$ cqu.edu.cn

a1251554424@qq.com,,772671075@qq.com process of intact marble specimens by digital image correlation (DIC) technology. Li et al. ${ }^{[8]}$ put forward a general DIC precision improvement algorithm, which has been applied to high-precision deformation measurement of rock mass with dynamic fractures.

In this study, to investigate the rock breakage mechanism of jointed rock masses under the disc cutters, strain fields and infrared temperature fields of jointed rock mass were monitored by using the DIC technology and infrared thermal imager. Subsequently, through comparative analysis, the change law of temperature field and strain field in the process of rock mass failure was proposed.

\section{Experimental methodology}

\subsection{Specimen preparation}

In order to observe the cracks of rock mass surface and temperature under the indentation of disc cutter, granite was selected as the test material. The specimen is cut into a plate shape with size of $200 \mathrm{~mm} \times 140 \mathrm{~mm} \times 30 \mathrm{~mm}$, as shown in Fig. 1. Furthermore, the joint planes that run throughout the specimens were manufactured. The joint spacing is set to be $50 \mathrm{~mm}$ and the joint dip angle is $30^{\circ}$. Subsequently, joints shall were filled with cement mortar. The basic mechanical parameters of jointed rock mass are shown in Table 1. 


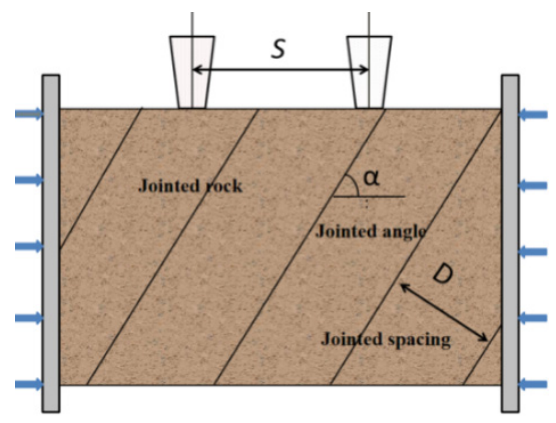

Fig. 1. Sketch map of rock sample geometric characteristics and cutter spacing

Table 1. Mechanical parameters of jointed rock mass

\begin{tabular}{|c|c|c|}
\hline Parameters & Granite & Joint plane \\
\hline $\begin{array}{c}\text { Density } \rho\left(\mathrm{g} / \mathrm{cm}^{3}\right) \\
(\mathrm{MPa})\end{array}$ & 2.6 & 2.1 \\
\hline $\begin{array}{c}\text { Uniaxial compressive strength } \sigma_{c} \\
\text { Tensile strength } \sigma_{t}(\mathrm{MPa})\end{array}$ & 127.4 & 29.3 \\
\hline Elastic modulus E (GPa) & 39.8 & 5.6 \\
\hline Cohesive strength c $(\mathrm{MPa})$ & 12.53 & 0.57 \\
\hline Internal friction angle $\left(^{\circ}\right)$ & 45 & 32 \\
\hline
\end{tabular}

\subsection{Experimental set up and test process}

The test device is composed of loading system, data acquisition system and operating system, as shown in Fig. 2. The loading system is WDAJ-600 shear rheological test system. The vertical and transverse loading capacity of oil cylinders reach $600 \mathrm{kN}$, and the adjustment range of loading rate is $0.1 \sim 100 \mathrm{kN} / \mathrm{min}$. The cutter used in this test represents the 17-inch constant cross-section disc cutter with a central angle of 19 . The cutter spacing is set to $80 \mathrm{~mm}$. H13 model steel with high hardness, which is commonly used with TBM cutter, is selected as the material. Its Rockwell hardness is $45 \sim 55 H R C$. The edge angle of the cutter is 20 , and the tip width is $12 \mathrm{~mm}$. The measurement system consists of DIC system and D384M infrared camera, which were placed on the front and behind the rock specimen, respectively. In detail, DIC system is composed of CCD camera, LED fill light and a high-performance computer, which is used to analyze the strain fields on the rock surface during the test. The main parameters of D384M infrared thermal imager are as follows: infrared resolution $384 \times 288$ pixels, infrared frame rate $12 \mathrm{fps}$, noise equivalent temperature difference $0.045 K$, and temperature measurement range-20 150C.

Before the test, confining pressure of $2 \mathrm{MPa}$ was applied to the specimen. Then the disc cutters penetrate into the specimen in the displacement controlled manner. The loading rate was set to be $0.1 \mathrm{~mm} / \mathrm{min}$. When the penetration depth reaches $10 \mathrm{~mm}$, the test terminates. During the indentation, displacement of disc cutters were recorded in a real time. Simultaneously, the specimens was monitored by DIC system and infrared camera. After the test, the data are analyzed by professional infrared radiation temperature analysis software, and the relevant analysis results are extracted from it.

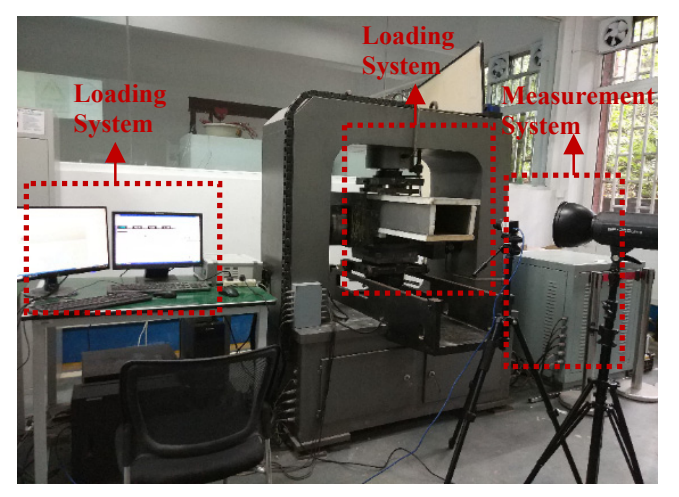

Fig. 2. Schematic diagram of experimental equipment

\section{Experimental results and discussions}

\subsection{Failure process of rock mass}

To explore the failure process of jointed rock mass, by disc cutter, normal force acting on the disc cutters were measured, as plotted in Fig. 3. According to this figure, the failure process of jointed rock mass can be divided into four stages: compaction stage, linear elasticity stage, residual failure transition stage and post-failure stage. Among them, in the compaction stage, when the cutter first comes into contact with the rock sample, the rock sample is gradually compacted, and the load curve is concave. After the penetration is about $0.5 \mathrm{~mm}$, the load curve enters the linear elastic stage. With the increase of cutter penetration, the intrusion force keeps increasing linearly, the rock mass is damaged after loading to the peak point, the main crack is formed, and the load drops sharply. Then, as the cutter continues to invade, the load curve shows obvious plastic deformation characteristics. In this process, the micro-cracks continue to expand and then communicate with the joint surface, and the load drops sharply again. After many residual damage transitions, it enters the post-damage stage.

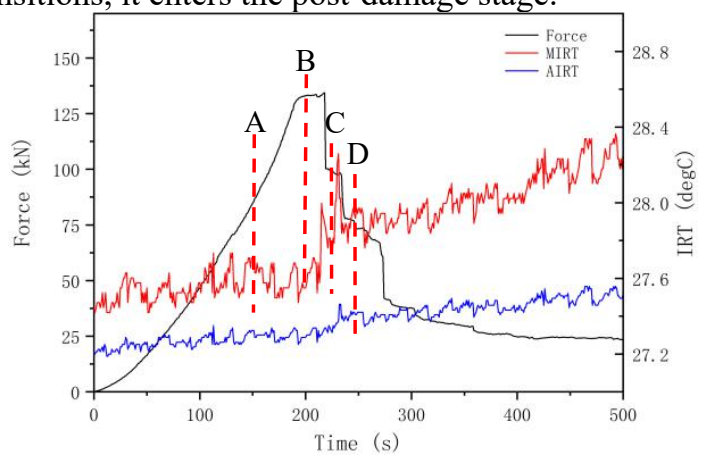

Fig. 3. Load-time curve of rock sample and corresponding average infrared radiation temperature

Furthermore, the cracking process were shown, as seen in Fig. 4. In the process of rock breaking, the compressive stress failure zone and micro-cracks appear 
immediately below the cutting edge, which is the initial rock breaking. With the continuous indentation of the cutters, the rock mass is crushed and cracked, and wing cracks begin to emerge from the joint surface and continue to expand. In the middle and late stage of cutter invasion, wing cracks and radial cracks under cutter meet with joint plane to form main cracks. At the later stage of cutter invasion, radial cracks spread to the deep, forming irregular crack propagation path, lateral cracks meeting and rock breaking.

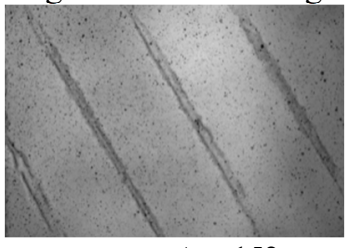

$A: t=152 s$

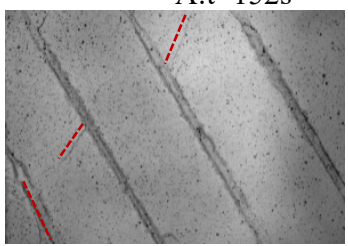

$C: t=224 s$

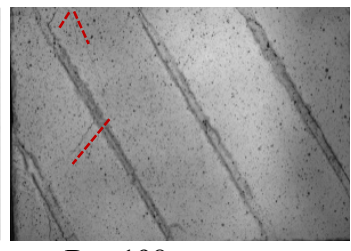

$\mathrm{B}: \mathrm{t}=198 \mathrm{~s}$

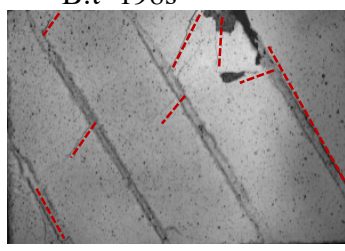

$\mathrm{D}: \mathrm{t}=248 \mathrm{~s}$
Fig. 4. Cracking process of rock samples at different times

\subsection{Characteristics of strain field in rock mass failure process}

Fig. 5 is shows the shear strain fields corresponding to marking points $\mathrm{A}, \mathrm{B}, \mathrm{C}$ and $\mathrm{D}$ under different loading levels. At point $\mathrm{A}$, it is seen that the deformation of the specimen is relatively uniform. However, at point B, obvious strain concentration area occurs at the joint plane, which indicates that the rock mass slips along the joint plane. Additionally, wing cracks begin to emerge at the joint surface. Consequently, highlighted shear strain localization zone exists at the wing cracks. As the indentation goes on, the wing cracks propagate continuously, the corresponding highlighted shear strain localization zone gradually extends to the direction perpendicular to the joint plane (point $\mathrm{C}$ ). The radial tension cracks under the cutter head continue to extend and penetrate the joint plane. At the same time, wing shear cracks extend diagonally along the specimen. Therefore, highlighted strain concentration area near the joint plane occurs gradually. With the strain localization zone continues to expand and extend, the jointed rock mass is damaged (point D).

From the variation of the strain field, it is concluded that the strain localization is an important feature of rock mass instability and failure, which indicates the crack initiation, propagation and coalescence.
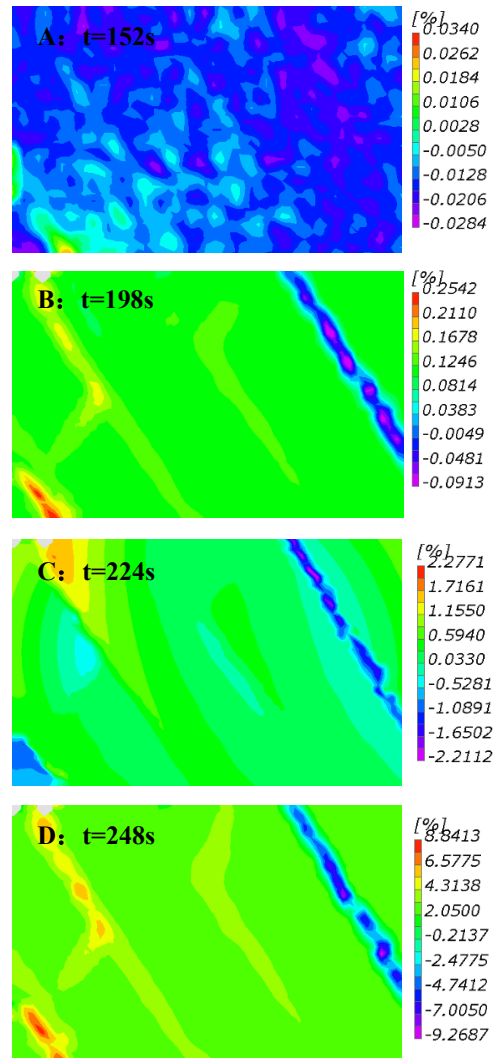

Fig. 5. Shear strain fields of rock sample at different times

\subsection{Characteristics of thermal infrared images during rock breaking process}

Similar with the strain field of the specimen, the thermal infrared images corresponding to identification points $\mathrm{A}$, $\mathrm{B}, \mathrm{C}$ and $\mathrm{D}$ is shown in Fig. 6 . As can be seen in this figure, no obvious differentiation was observed before the peak load. When it is loaded to the peak load (marking point B), a local heating zone occurs along the joint plane because of the frictional heat effect. Besides, propagation of the shear cracks can also cause the increase in infrared radiation temperature. However, tensile fracture can not lead to frictional heat, so it has little impact on the infrared radiation of rock specimens.

According to the curve of average infrared radiation temperature (AIRT) shown in Fig. 3, MIRT grows slowly in the initial loading stage, which may be caused by the pore gas desorbing-escaping effect and thermoelastic effect. Specifically, gas is sealed and adsorbed in the pores of the rock sample. Under the loading, the pores are compacted, causing the gas in the pores escapes. This process needs to dissipate energy, resulting in the decrease of infrared radiation temperature around the pores by $\Delta T<0$, i.e. the gas escape effect in the pores. On the other hand, there is thermoelastic effect. Before the stress reaches the peak value, the temperature of thermoelastic effect increases more than that of gas escaping process, i.e. the temperature of infrared radiation on the rock surface increases continuously. At the linear elasticity stage, the AIRT rises greatly. Because the tension crack has limited propagation, the shear crack initiated generates frictional heat generation effect, and the infrared 
radiation temperature in the vicinity rises sharply. At the peak load, obvious fracture appears, causing the energy stored in the specimen releases. So the temperature drops rapidly. This phenomenon occurs repeatedly in the residual failure transition stage until the rock mass is completely destroyed.
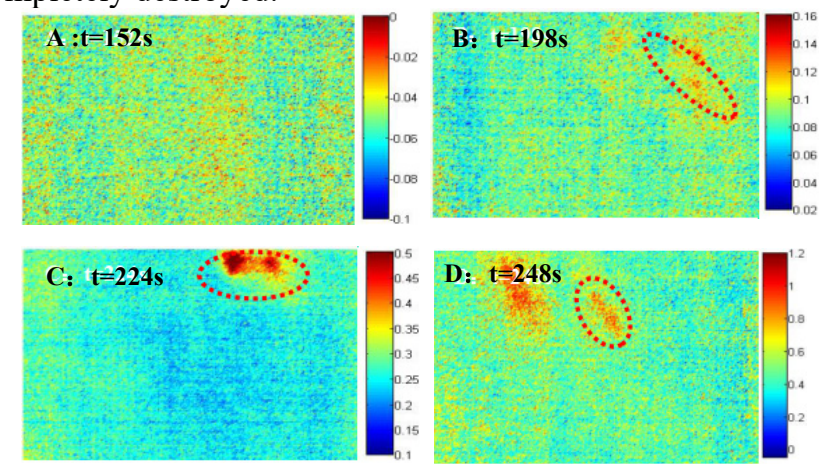

Fig. 6. Infrared temperature fields of rock sample at different times

\section{Conclusions}

In this paper, indentation test was performed on the jointed rock mass. Subsequently, the failure process of the specimen was investigated by means of the strain fields and thermal infrared images. The following conclusions can be drawn:

(1) The failure process of jointed rock mass can be divided into four stages according to different load levels: compaction stage, linear elastic stage, residual failure transition stage and post-failure stage. Different stages show different characteristics of strain fields and thermal infrared images. The process of crack initiation, propagation and penetration is accompanied by different multi-source abnormal information.

(2) The failure of jointed rock mass is characteristic by highlighted strain localization, which is an important precursor of rock mass instability and failure. It is possible to predict the initiation, propagation and through path of macroscopic cracks from the change of strain fields. The failure of jointed rock mass is dominated by the shear failure of joint surface, which is marked by the penetration of shear crack, wing crack and radial crack.

(3) There are two main types of cracks during loading process, i.e. tensile and shear cracks. During the propagation of tensile fracture, no obvious change on thermal image is found. However, for the shear cracks, abnormal temperature increase on the thermal image can be seen. The local warming anomaly is an important infrared precursor of rock fracture and instability.

\section{Acknowledgments}

The financial support from Project supported by graduate research and innovation foundation of Chongqing, China (Grant No.CYB19015), Natural Science Fund of China (Nos. 51879016) and the National Key R\&D Program of China, No.2018YFC1505504) are greatly appreciated.

\section{References}

1. Gnirk, P.F. (1966) An experimental study of indexed single bit-tooth penetration into dry rock at confining pressures of 0 to 7500 psi. In: Proceedings of the First Congress International Society on Rock Mechanics. Lisbon. pp. 121-129.

2. Maurer, W.C. (1966) The state of rock mechanics knowledge in drilling. In: The 8 The US Symposium on Rock Mechanics (USRMS). New York. pp. 355395.

3. Sikarskie, D.L., Altier, N. J. (1973) The formation of chips in the penetration of elastic-brittle materials(rock). Jounal of Applied Mechanics. 791798.

4. Sikarskie, D.L., Cheatham,J.B. (1973) Penetration Problems in Rock Mechanics. 41-47.

5. Paul, B., Sikarskie, D.L. (1965) A preliminary theory of static penetration of a rigid wedge into a brittle material. Transaction of the Society of Mining Engineers. 372-383.

6. Tian, B.J., Liu, S.J., Zhang, Y.B. Liang, P., Liu, X.X. (2016) Laboratory simulation of temporospatial evolution characteristics of infrared radiation in the process of rockburst in granite tunnel. Rock and Soil Mechanics, 37(3): 711-718.

7. Song, Y.M., Ma, S.P., Yang X.B., Wang, X. (2011) Experimental investigation on failure of rock by digital speckle correlation methods. Chinese Journal of Rock Mechanics and Engineering, 30(1): 170-175.

8. Li, Y.H., Lin, Z.B., Jing, H.W., Yang, S.Q. (2015) High-accuracy digital speckle correlation method for rock with dynamic fractures. Chinese Journal of Geotechnical Engineering, 34(6): 1061-1068. 